\title{
Control Strategies for Automated Storage/Retrieval Systems
}

\author{
Jeroen van den Berg and Noud Gademann \\ University of Twente, The Netherlands
}

\begin{abstract}
Automated Storage/Retrieval Systems (AS/RSs) are widely used in manufacturing systems and distribution centers. A typical system is comprised of multiple aisles with (high-rise) storage racks alongsides and multiple storage/retrieval (S/R) machines operating on one or more aisles that transfer items from an input/output (I/O) station to the storage positions and vice versa. The throughput of an AS/RS, i.e., the maximum rate at which it is possible to process storage and retrieval requests, depends on the control strategies that are incorporated.
\end{abstract}

One such strategy that is discussed, is concerned with the allocation of items to storage positions. Some well known allocation-rules are: closest open location, class-based allocation (ABC), fullturnover based allocation and the cube-per-order index rule. The latter three make use of the idea that items with a high turnover frequency should be assigned to positions close to the $\mathrm{I} / \mathrm{O}$ station.

A second strategy that is discussed, is concerned with scheduling storage and retrieval requests. When the S/R machine travels from the $\mathrm{I} / \mathrm{O}$ station, performs a storage or retrieval and returns to the I/O station, this is called a single command cycle. When successively a storage and a retrieval are performed within the same cycle then this is referred to as a dual command cycle. Generally, the S/R machine has a unit load capacity, so that it is not possible to perform more storages or retrievals during one command cycle. When several storage and retrieval requests are waiting to be processed, the total travel time of the S/R machine can be minimized by pairing requests to facilitate dual command cycles. Several allocation-rules as well as scheduling strategies are compared. 